\title{
PENGARUH PELAYANAN DAN PRODUK TABUNGAN BAGI HASIL TERHADAP KEPUTUSAN MENABUNG PADA BANK SYARIAH MANDIRI CABANG PASURUAN
}

\author{
Efi Endang Dwi Setyorini1) \\ 1)Sekolah Tinggi Ilmu Ekonomi Gempol \\ 1) efieds@ymail.com
}

\begin{abstract}
Abstrak. Penelitian ini bertujuan untuk menguji pengaruh pelayanan dan produk tabungan bagi hasil terhadap keputusan menabung pada Bank Syariah Mandiri Cabang Pasuruan. Untuk variabel dependen $(\mathrm{Y})$ dalam penelitian ini adalah keputusan menabung. Untuk variabel independen (X) meliputi, pelayanan (X1) dan produk tabungan bagi hasil (X2). Sampel yang digunakan sebanyak 100 orang dengan pengambilan sampel menggunakan metode random sampling. Penelitian ini menggunakan metode kuantitatif. Analisis data dalam penelitian ini menggunakan analisis Regresi Linier Berganda, uji asumsi klasik, Uji signifikansi dan uji ketepatan model. Dari hasil penelitian ini dapat disimpulkan berdasarkan uji t, variabel pelayanan (X1), produk tabungan bagi hasil (X2) memiliki pengaruh terhadap keputusan menabung $(\mathrm{Y})$.
\end{abstract}

Kata kunci : Keputusan Menabung, Pelayanan, Produk Tabungan Bagi Hasil

\begin{abstract}
This study aims to examine the effect of knowledge, location, quality of service, profit sharing on the decision to save at Bank Syariah Mandiri Pasuruan Branch. For the dependent variable $(Y)$ in this study is the decision to save. For independent variables (X) include, quality of service (X1), and profit sharing (X2). The sample used was 100 people with sampling using random sampling method. This study uses quantitative methods. Data analysis in this study uses multiple linear regression analysis, classical assumption test, significance test and model accuracy test. From the results of this study can be concluded based on the T test, service quality variable (X1), profit sharing (X2) has an influence on saving decisions (Y).
\end{abstract}

Keywords: Savings Decisions, Services, profit sharing.

\section{PENDAHULUAN}

\section{Latar Belakang}

Perkembangan peran perbankan syariah di Indonesia tidak terlepas dari sistem perbankan di Indonesia secara umum. Sistem perbankan syariah diatur dalam Undang-undang No.10 tahun 1998 dimana Bank Umum adalah bank yang melaksanakan kegiatan usaha secara konvensional atau berdasarkan prinsip yariah yang kegiatannya memberikan jasa dalam lalu lintas pembayaran. Peran bank syariah dalam memacu pertumbuhan perekonomian di Indonesia semakin strategis dalam rangka mewu-judkan struktur perekonomian yang semakin berimbang. 
Bank syariah perlu meningkatkan kualitas layanan yang baik agar dapat bersaing dengan bank konvensional karena semakin baik kualitas layanan yang diberikan bank syariah maka nasabah akan merasa puas. Apabila pelayanan yang diterima atau dirasakan sesuai dengan yang diharapkan maka kualitas pelayanan dipersepsikan baik dan memuaskan. Artinya, kualitas pelayanan yang baik menyebabkan tingkat kepuasan meningkat, sebaliknya kualitas pelayanan yang buruk mengakibatkan keputusan menabung juga semakin rendah. Dengan demikian, baik buruknya kualitas pelayanan yang diberikan tergantung pada kemampuan penyedia jasa dalam memenuhi harapan pelanggannya secara konsisten.

Selain itu juga ada permasalahan dalam hal pembagian bagi hasil produk tabungan yang dirasakan oleh nasabah. Nasabah dipengaruhi oleh tingkat keuntungan atau manfaat yang akan diperolehnya dari produk tabungan Mudharabah tersebut. Daulay. ${ }^{1}$ Nasabah cenderung akan memilih pembagian bagi hasil yang lebih besar oleh bank-bank syariah yang namanya sudah membooming dan memiliki nasabah yang banyak.

Keputusan menabung penting untuk diukur, agar perusahaan dalam hal ini bank syariah dapat mengetahui atribut apa dari suatu produk yang dapat memuaskan nasabah. Pengetahuan tentang persepsi nasabah akan membantu bank syariah dalam memberikan pelayanan yang terbaik kepada nasabahnya, sehingga nasabah menjadi puas dan dapat meningkatkan dana pihak ketiga pada Bank Syariah.

Begitu pun PT. Bank Syariah Mandiri, dimana keputusan menabung yang mempercayakan dananya di tabungan Mudharabah menjadi hal yang utama. Namun apakah kualitas jasa atau pelayanannya dan produk tabungan bagi hasil yang diberikan sama dengan bank syariah lainnya. Belum tentu, karena tingkat kenyamanan tinggi pun belum menjamin kepuasan serta kepercayaan nasabah dalam mempercayai bank dalam pengelolaan dana maupun margin bagi hasilnya.

\section{METODE PENELITIAN}

\section{Jenis dan Sumber Data}

Dalam penelitian ini teknik pengam-bilan sampel dilakukan dengan menggunakan teknik purposive sampling. Pengambilan sampel secara purpo-sive sampling didasarkan pada suatu pertimbangan tertentu yang dibuat oleh peneliti berdasarkan ciri atau si-fat populasi yang sudah diketahui sebelumnya. Jumlah sampel yang digunakan dalam penelitian ini sebanyak

${ }^{1}$ Daulay, R. (2010). Analisis Pelayanan Dan Bagi Hasil Terhadap Keputusan Menabung Nasabah Pada Bank Syariah Di Kota Medan. Jurnal Manajemen \& Bisnis, Vol.10, No.01, 1693-7619. 
100 anggota kelompok pengujian di Pasuruan yang menjadi nasabah bank syariah Mandiri Cabang Pasuruan.

Dalam penelitian ini data dan sumber data yang digunakan, yaitu data primer untuk menggali informasi langsung dari responden. Teknik pengumpulan data yang digunakan dalam penelitian adalah dengan metode kuesioner yaitu memberikan daftar pertanyaan terstruktur yang disesuaikan de-ngan materi penelitian untuk diisi oleh responden, yang kemudian jawaban dari responden dianalisis. Skala yang digunakan adalah Skala Likert.

\section{Metode Analisis Data}

Dalam penelitian ini metode analisis data yang digunakan adalah regresi linier berganda karena penelitian ini dirancang untuk meneliti pengaruh variabel independen terhadap variabel dependen. Dengan demikian mo-del analisis dapat dinyatakan sebagai berikut:

$$
\mathbf{Y}=\mathbf{a}+\mathbf{b}_{1} \mathbf{X}_{1}+\mathbf{b}_{2} \mathbf{X}_{2}+\mathbf{e}
$$

Level pengujian menggunakan alpha

( $\alpha$ ) 5\% dan pengolahan dengan software SPSS versi 22.

\section{Pengujian Hipotesis}

\section{Uji t (Uji Parsial)}

Uji t yaitu suatu uji untuk mengetahui signifikansi pengaruh variabel inde-penden secara parsial atau individual terhadap variabel dependen. Kriteria pengujian:

Apabila sig $\mathrm{t} \leq 0,05$, maka $\mathrm{H}_{\mathrm{o}}$ ditolak dan Ha diterima pada $(\alpha=0,05)$.

Apabila sig t $>0,05$, maka Ho diterima dan Ha ditolak pada $(\alpha=0,05)$.

\section{PEMBAHASAN DAN HASIL PENELITIAN}

\section{Perilaku Konsumen}

Perilaku konsumen adalah tindakan yang langsung terlibat dalam mendapatkan, mengkonsumsi, dan menghabiskan produk atau jasa, termasuk proses keputusan yang mendahului dan menyusuli tindakan ini. Untuk memahami konsumen dan mengembangkan strategi pemasaran yang tepat perusahaan harus memahami apa yang konsumen pikirkan (kognisi) dan konsumen rasakan (pengaruh), apa yang konsumen lakukan (perilaku), dan dimana konsumen (kejadian sekitar) yang mempengaruhi serta dipengaruhi apa yang dipikirkan, dirasa, dan dilakukan konsumen.

Perilaku konsumen didefinisikan sebagai studi tentang unit pembelian dan proses pertukaran yang melibatkan perolehan, konsumsi, dan pembuangan barang, jasa, pengalaman, serta ide-ide. 
Keputusan pembelian dari pembeli sangat dipengaruhi oleh faktor kebudayaan, sosial, pribadi, dan psikologi dari pembeli. Sebagian besar adalah faktor yang tidak dapat dikendalikan oleh pemasar, tetapi harus benar-benar diperhitungkan. Ada 4 (empat) faktor yang mempengaruhi perilaku konsumen yaitu: Kebudayaan, Sosial, Pribadi dan Psikologi.

Keputusan adalah perihal yang berkaitan dengan putusan, segala putusan yang telah ditetapkan. Menabung adalah menyimpan uang (di celengan, pos, dsb). (Kamus Besar: 656).

Keputusan membeli yaitu membeli merek yang paling disukai. Namun, dua faktor dapat berada di antara niat pembelian dan keputusan pembelian. Faktor pertama adalah sikap orang lain. Sejauh mana sikap orang lain mempengaruhi alternatif yang disukai seseorang tergantung pada dua hal, yaitu: Intensitas pendirian negatif orang lain terhadap alternatif yang disukai konsumen, dan motivasi konsumen untuk menuruti orang lain. Faktor kedua adalah faktor situasi yang tidak terantisipasi yang dapat muncul mengubah niat pembeli.

\section{Kualitas Pelayanan}

Pasuraman mendefinisikan kualitas pelayanan sebagai suatu konsep yang secara tepat mewakili inti dari kinerja suatu pelayanan yaitu perbandingan terhadap keterhandalan (excellence) dalam service encounter yang dilakukan oleh konsumen. Setiawan. ${ }^{2}$

Kualitas Pelayanan adalah tingkat keunggulan yang diharapkan dan pengendalian atas tingkat keunggulan tersebut untuk memenuhi keinginan pelanggan". ${ }^{3}$ Apabila pelayanan yang diterima atau dirasakan oleh nasabah sesuai dengan harapan, maka kualitas pelayanan dipersepsikan baik dan memuaskan, Sebaliknya apabila pelayanan yang diterima oleh nasabah tidak sesuai dengan harapan, maka kualitas pelayanan dipersepsikan tidak baik dan tidak memuaskan. Menurut Pasuraman dalam Setiawan terdapat 5 (lima) dimensi Service Quality yaitu sebagai berikut : Tangibles atau bukti fisik, Reliability atau keandalan, Responsive-ness atau ketanggapan, Assurance atau jaminan, dan Empathy.

\section{Produk Tabungan Bagi Hasil}

Bagi hasil merupakan dimana kedua belah pihak akan berbagi keuntungan sesuai dengan perjanjian yang telah disepakati dimana bagi hasil mensyaratkan kerjasama pemilik modal dengan usaha/kerja untuk kepentingan yang saling menguntungkan kedua belah pihak. Sebagai konsekuensi dari kerjasama adalah memikul risiko, baik untung maupun rugi. Jika untung yang diperoleh besar maka penyedia dana dan pekerja menikmati bersama sesuai dengan kesepakatan sebelumnya dan jika rugi maka harus dirasakan bersama pula.

\footnotetext{
2 Setiawan dan Kusrini Dwi Endah (2010). Ekonometrika. (Yogyakarta: Andi Offset., 2011) hal. 216-217

3 Ibid. hal. 220-221
} 
Prinsip bagi hasil adalah aturan yang digunakan sebagai dasar pembagian hasil usaha adalah laba bruto (gross profit) bukan total pendapatan usaha (omzet). Ada 2 (dua) jenis prinsip bagi hasil yang digunakan dalam produk tabungan bagi hasil di Bank Syariah, sebagai berikut: Profit Sharing dan Revenue Sharing.

Setiap pembelian produk jasa maupun barang konsumen dipengaruhi oleh tingkat keuntungan atau manfaat yang akan diperolehnya dari produk tersebut. Adapun tingkat keuntungan yang akan diperoleh konsumen pada jasa bank terutama bank syariah adalah bagi hasil. Terdapat 4 dimensi bagi hasil yaitu persentase, bagi untung \& bagi rugi, jaminan, dan menentukan besarnya nisbah. ${ }^{4}$ Yaitu : Presentase, Bagi untung dan bagi rugi, Jaminan dan Menetukan besarnya nsibah.

\section{Bagi Hasil}

Menurut Antonio bagi hasil adalah suatu sistem pengolahan dana dalam perekonomian Islam yakni pembagian hasil usaha antara pemilik modal (shahibul maal) dan pengelola (Mudharib) ${ }^{5}$. Muhammad menjelaskan "pelarangan riba dalam Islam adalah suatu penolakan terhadap timbulnya risiko finansial tambahan yang ditetapkan dalam transaksi uang atau modal maupun jual beli yang dibebankan kepada satu pihak saja sedangkan pihak yang lain dijamin keuntungannya"6. Hal ini mengindikasikan perbankan Syariah menganut sistem bagi hasil dalam proses kegiatannya dan mengharamkan bunga karena mengandung unsur riba. Distribusi pembagian hasil usaha bank syariah dengan nasabah penghimpunan dana hanya didasarkan pada akad mudharabah, pembagian hasil usaha dilakukan bedasarkan pada nisbah yang disepakati pada awal akad7.

Berdasarkan uraian di atas dapat di-rumuskan hipotesis sebagai berikut:

H1: Pelayanan berpengaruh positif terhadap keputusan menabung pada Bank Syariah Mandiri Cabang Pasuruan.

H2: Produk tabungan bagi hasil berpengaruh positif terhadap keputusan menabung pada Bank Syariah Mandiri Cabang Pasuruan.

H: Pelayanan dan Produk tabungan Bagi Hasil secara simultan berpenga-ruh positif terhadap keputusan menabung pada Bank Syariah Mandiri Cabang Pasuruan.

\footnotetext{
${ }^{4}$ Karim, A. (2013). Analisis Fiqih Dan Keuangan. (Jakarta: Pt Grafindo Persada, 2011), hal. 206.

${ }^{5}$ Antonio, Muhammad.S. (2001). Bank Syariah Dari Teori Dan Praktik. (Jakarta: Gema Insani Press, 2013) hal. 90.

${ }^{6}$ Muhammad. (2004). Teknik Perhitungan Bagi Hasil dan Profit Margin pada Bank Syariah. (Yogyakarta: UII Press, 2012), hal. 121.

${ }^{7}$ Wiroso. (2013). Prinsip Dasar Perbankan Syariah. (Jakarta : IAI, 2013), hal. 89
} 


\subsection{Hasil Analisis}

Hasil pengujian terhadap model regresi berganda terhadap variabel pelayanan (X1), produk tabungan bagi hasil (X2), yang mempengaruhi keputusan mena-bung pada Bank syariah Mandiri (Y) dapat dilihat dalam tabel berikut:

Tabel 1. Hasil Regresi Faktor-Faktor Mempengaruhi Loyalitas Nasabah.

\begin{tabular}{|l|l|l|}
\hline $\begin{array}{c}\text { Variabel } \\
\text { Independen }\end{array}$ & $\begin{array}{c}\text { Koefisien } \\
\text { Regresi }\end{array}$ & $\begin{array}{c}\text { t- } \\
\text { hitung }\end{array}$ \\
\hline Konstanta & 0,191 & 0.115 \\
\hline Pelayanan & 0.220 & 2.373 \\
\hline Bagi Hasil & 0,332 & 4.038 \\
\hline F hitung & 28,646 & \\
\hline Sig. F & 0,000 & \\
\hline Adjusted R2 & 0,528 & \\
\hline
\end{tabular}

Dengan memperhatikan model regresi dan hasil regresi linear berganda maka didapatkan persamaan faktor-faktor yang mempengaruhi keputusan menabung nasabah sebagai berikut:

$$
\mathrm{Y}=0,191+0,220 \mathrm{X} 1+0,332 \mathrm{X} 2
$$

Dari hasil perhitungan data yang telah dilakukan, maka hipotesis pertama yang menyatakan bahwa pelayanan (X1) mempunyai pengaruh yang positif terhadap keputusan menabung dengan koefisien regresi sebesar 0,220. Dengan adanya pengaruh yang positif ini, berarti bahwa antara pelayanan dan keputusan menabung menunjukkan hubungan yang positif. Hasil pengujian signifikansi menunjukkan bahwa variabel pelayanan (X1) terdapat nilai sig $t$ sebesar 0,000 yang berarti $p$ value < 0,05. Dengan demikian hipotesis pertama yang menyatakan bahwa variabel pelayanan berpengaruh positif dan signifikan terhadap keputusan menabung dalam menggunakan perbankan syariah dapat terbukti.

Hipotesis kedua menyatakan bahwa produk tabungan bagi hasil (X2) mempunyai pengaruh yang positif terhadap keputusan menabung dengan koefisien regresi sebesar 0,332. Dengan adanya pengaruh yang positif ini, berarti bahwa antara produk tabungan bagi hasil dan keputusan menabung menunjukkan hubungan yang positif. Hasil pengujian signifikansi menunjukkan bahwa variabel produk tabungan 
bagi hasil (X2) terdapat nilai sig $t$ sebesar 0,000 yang berarti $p$ value $<0,05$. Dengan demikian hipotesis kedua yang menyatakan bahwa variabel produk tabungan bagi hasil berpengaruh positif dan signifikan terhadap keputusan menabung dalam menggunakan perbankan syariah Mandiri dapat terbukti.

Hipotesis ketiga menyatakan bahwa pelayanan (X1) dan produk tabungan bagi hasil (X2) secara simultan mempu-nyai pengaruh yang positif terhadap keputusan menabung (Y). Hasil uji regresi berganda menunjukkan bahwa koefisien $\mathrm{F}$ hitung sebesar 28,646. Dengan adanya pengaruh yang positif ini, berarti bahwa antara pelayanan dan produk tabungan bagi hasil secara simultan menunjukkan hubungan yang positif terhadap keputusan menabung.

Hasil pengujian signifikansi menunjuk-kan bahwa secara simultan variabel independen terdapat nilai sig F sebesar 0,000 yang berarti $\mathrm{p}$ value $<0,05$. Dengan demikian hipotesis ketiga yang menyatakan bahwa pelayanan dan produk tabungan bagi hasil secara simultan mempunyai pengaruh yang positif dan signifikan terhadap keputusan menabung perbankan syariah Mandiri dapat terbukti.

\subsection{Pembahasan}

Berdasarkan hasil analisis di atas diketahui bahwa variabel pelayanan (X1), produk tabungan bagi hasil (X2) berpengaruh positif dan signifikan terhadap keputusan menabung perbankan syariah Mandiri (Y). Hasil penelitian ini sesuai dengan penelitian Morgan dan Hunt (2010), yang mengemukakan bahwa pelayanan merupakan elemen penting yang mempengaruhi tingkat keputusan menabung. Pelayanan terhadap penyedia jasa akan meningkatkan keputusan menabung terhadap penyedia jasa, semakin tinggi tingkat pelayanan terhadap penyedia jasa maka semakin tinggi pula tingkat keputusan menabung yang mereka miliki.

Variabel produk tabungan bagi hasil (X2) berpengaruh positif dan signifikan terhadap keputusan menabung menggunakan perbankan syariah Mandiri (Y). Hasil penelitian ini sesuai dengan penelitian Bloemer (2010), yang menyimpulkan bahwa variabel produk tabungan bagi hasil memiliki pengaruh positif dan signifikan terhadap keputusan menabung, artinya seorang nasabah bank akan merasa puas setelah melakukan transaksi melalui bank dan akan menimbulkan keinginan untuk menggunakan layanan tersebut dikemudian hari.

Kedua variabel independen pelayanan (X1), dan produk tabungan bagi hasil (X2) secara simultan mempunyai penga-ruh yang positif dan signifikan terhadap keputusan 
menabung (Y). Hal ini dibuktikan dengan hasil uji regresi berganda menunjukkan bahwa koefisien F hitung sebesar 28,646. Dengan adanya pengaruh yang positif ini, berarti bahwa antara pelayanan dan produk tabungan bagi hasil secara simultan menunjukkan hubungan yang positif terhadap keputusan menabung. Hasil pengujian signifikansi menunjukkan bahwa secara simultan variabel independen terdapat nilai sig F sebesar 0,000 yang berarti $p$ value $<0,05$.

\section{KESIMPULAN DAN SARAN}

\section{Kesimpulan}

Berdasarkan hasil penelitian ini dapat disimpulkan bahwa pelayanan dan produk tabungan bagi hasil baik secara parsial maupun simultan berpengaruh positif dan signifikan terhadap keputusan menabung perbankan syariah Mandiri. Adapun sumbangan efektif kedua variabel independen terhadap variabel dependen sebesar 52,8\% dan sisanya 47,2 \% yang dipengaruhi oleh variabel lain yang tidak diteliti.

\section{Saran}

Bagi manajemen bank syariah Mandiri, hendaknya melakukan survei berkala mengenai bagaimana keputusan menabung. Selain itu juga meningkatkan pelayanan melalui peningkatan kemampuan karyawan bank dalam komunikasi bagi hasil dengan nasabah guna meningkatkan kualitas pelayanan yang akan berdampak pada keputusan menabung dan loyalitas nasabah. 


\section{DAFTAR PUSTAKA}

Antonio, Muhammad.S. (2001). Bank Syariah Dari Teori Dan Praktik. Jakarta: Gema Insani Press.

Daulay, R. (2010). Analisis Pelayanan Dan Bagi Hasil Terhadap Keputusan Menabung Nasabah Pada Bank Syariah Di Kota Medan. Jurnal Manajemen \& Bisnis, Vol.10, No.01, 1693-7619.

Karim, A. (2013). Analisis Fiqih Dan Keuangan. Jakarta: Pt Grafindo Persada.

Setiawan dan Kusrini Dwi Endah (2010). Ekonometrika. Yogyakarta: Andi Offset.

Muhammad. (2004). Teknik Perhitungan Bagi Hasil dan Profit Margin pada Bank Syariah. Yogyakarta: UII Press.

Wiroso. (2013). Prinsip Dasar Perbankan Syariah. Jakarta : IAI. 